\title{
A Survey of Major HR Challenges in the Mature and Emerging Industries A Comparison between IT and Banking Industries of Pakistan
}

\author{
Afifa Balagam* and Shadab Fariduddin \\ Afifa.balagam@gmail.com \\ SZABIST \\ Karachi, Pakistan
}

\begin{abstract}
The study explores the major HR challenges faced by an emerging sector like IT Solutions \& Services and by a mature sector like banking. It identifies the lessons that can be learnt from a mature sector and how challenges can be avoided by an emerging sector for the betterment of the industry.

This study is qualitative and has been conducted based on primary data through structured questionnaires from 10 banks and 50 IT companies.

The findings of the study are that all banks possess a formal and dedicated HR department and they have sophisticated processes, procedures and policies that have evolved over the period of time. Compared to that, very few IT companies have shown importance of HR, as they have only few people in their HR department. Majority of the IT firms do not have a formal and dedicated HR department and thus, HR people are not playing any strategic role in the organization.
\end{abstract}

Keywords: IT in Pakistan, challenges of IT sector, global $H R$ issues, change management, emerging industries, growth in Pakistan, Pakistani economy, banking sector

\section{INTRODUCTION}

Pakistan is a country, which is showing a positive economic growth. As the economy is growing, there is a massive boost in the HR requirement and planning. The emergence of several HR firms and recruitment agencies in Pakistan is a vital proof of this fact.

HR is a hot issue of the $21^{\text {st }}$ century, and as the new sectors are emerging, the dynamics of the markets are changing and we are facing a paradigm shift when it comes to HR Demand and Supply, HR Mobility, Retention and Expectations of employers' vis-à-vis employees and vice versa.

Multiple HR problems and challenges are being discussed on various forums; articles and several employers talk about-facing issues of acquisition and retention of HR.

The objective of this study is to understand and identify the major HR challenges faced by an emerging sector, like IT Solutions \& Services and by a mature sector like Banking. The study will be able to understand and identify the reasons for these challenges and to what extent the challenges in both the sectors differ.

This globalization and overwhelming knowledge of the Human Resources (professionals) is posing a great challenge for employers, especially their Human Resource Department. Pakistan is a country where several sectors are emerging and $\mathrm{HR}$ is being diversified. The study will play a critical role, as organizations will be able to plan better and align their strategies accordingly. On the academic side, educators will be able to address the industry issues in a better manner and in turn will be able to update the academic syllabus offered at bachelors and masters level.

A qualitative study has been conducted based on primary source research through structured questionnaires along with some secondary data research. Questionnaires were developed covering the HR challenges on multiple phases of industry life cycle. Sampling has been done on convenience basis. The questionnaire was sent to 10 banks and 50 IT companies, out of which 6 banks and 19 IT companies responded.

The major limitation faced was time. Apart from that, lack of responses from most of the companies, confidentiality issue and lack of formal HR department in few IT firms were also some of the limitations.

\section{LITERATURE REVIEW}

The initial inspiration was taken from the study conducted by PricewaterhouseCoopers in 2005, on behalf of World Federation of Personnel Management Associations (WFPMA), to identify Global HR Challenges [1]. Apart from that, a lot of literature was referred from different research journals and studies conducted by authorized bodies. Since the topic of HR issues and challenges is most crucial, both on the national as well as on international level, various articles and papers were also studied to grasp the concept of industry dynamics, pitfalls and challenges [1].

Some of the generic HR challenges that we came across through different studies are attracting the right HR, recruitment and availability of proper resource, knowledge management, change management, staffing: retention,

\footnotetext{
${ }^{*}$ Currently enrolled in MSMS program at SZABIST, Karachi Journal of Independent Studies and Research (JISR) - Management and Social Sciences \& Economics Volume 6, Number 2, July 2008
} 
industrial relations, leadership \& learning and development, compliance with standards \& norms, restructuring, organizational effectiveness, outsourcing, staffing: international mobility of employees, succession planning, etc [1].

\subsection{HR Challenges for Banking Industry}

The banking industry throughout the world is facing newer challenges in terms of narrowing spreads, new banking products, players, mergers and acquisitions. In terms of Industry Life Cycle, this sector is in the mature stage and the technological changes are pushing this sector into renewal stage. Globally, the change is evident and even in Pakistan the boom in the banking sector is the testament of this fact that how banking is about to get revolutionized [2].

The need for introduction of new technology in the banking sector and the importance of skill building and intellectual capital formation in the banking industry are also equally important. The following are few of the main challenges in banking sector: The Changing Paradigm of Banking, Change Management, Financial Intermediation, Market Discipline, Adopting International Standards, Technology Banking, Rural Banking, Human Resource Development, and Retention of Resources [3].

\subsection{HR Challenges for IT Industry}

Information Technology is a thriving sector world wide compared to different commercial sectors. In Pakistan, Information Technology is there since last 15 years and currently this sector is moving from the Growth Stage to the Rapid Growth Stage. The actual growth was observed after the incident of 9/11, after which the IT industry nearly collapsed and was redeveloped. Since then, it is growing at a remarkable pace. Most of the challenges that were and are usually faced in the IT industry in Asia, USA and Europe are recruitment planning, performance management, training and development, compensation and reward, demand-supply gap, integrating HR strategy with business strategy, encouraging quality and customer focus, up-gradation of skills through re-training, skill acquisition and retention etc [4].

Each and every industry possesses different dynamics, different product and service cycle. Since the HR issues are very much dependent upon the industry dynamics such as nature of business, product life cycle etc, similarly they also face different kinds of challenges [5].

\subsection{Mature vs. Emerging Industry}

The industry lifecycle comprises of 5 distinct stages namely: inception or dormant stage with low numbers of competitors enjoying high monopoly profits, rapid growth or "takeoff" stage with soaring entry and virtually nonexistent exit from the market, growth or high turnover stage with many firms entering the market and leaving it, mature "shakeout" stage with mass exit via mergers, bankruptcies etc and stabilization stage during which a stable oligopoly emerges [6].

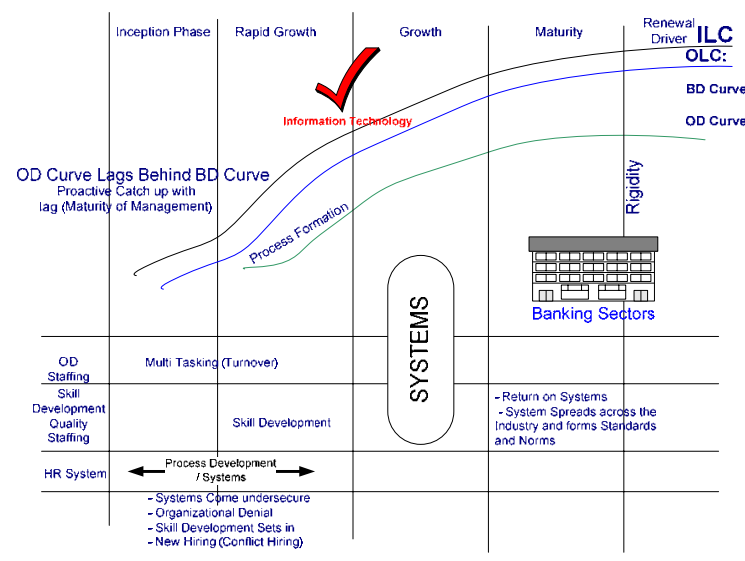

Figure 1: Industry Life Cycle

Industry Life Cycle depicts the stages through which companies pass and accordingly what issues they face during each stage of the cycle.

When an industry is in its 'inception phase', the issues of attracting the right $\mathrm{HR}$ is there. At this stage the companies develop team, develop skill and initiates development of HR system. Organization Life Cycle (OLC) also starts developing at this stage, which comprises of Organization Development Curve (ODC) and Business Development Curve (BDC). It is worth mentioning that in 80 to $90 \%$ of the companies, Organization Development starts after crises [6].

The Business Development Curve shows the stages where organization starts making the revenue. As the name itself depicts 'Business Development' starts after some time and continues to grow as shown in the graph. Usually, all three curves show progression as they move from the inception towards the maturity stage [6], [7], [8].

Moving towards the 'rapid growth phase', the company faces multitasking. Professionals carry out multiple jobs and their skills are further developed. With money at hand, companies then hire better-qualified people. The new hiring leads to conflict between the management and old employees, resulting in employee turnover. This is the stage where an organizational culture takes deeper roots.

In growth stage, the business is booming and systems develop and start getting improved and mature. More hiring is done and employee turnover goes hand in hand. However, processes are getting mature; therefore, turnover posses a problem, but not a major one. 
In maturity phase, the processes are mature and now the companies get return on their processes as well. Systems being well tested and mature are followed across the industry and become norms and standards [6].

A mature industry evolves in a long time and passes through various stages and thus characterized by major players in the industry, well established norms and best practices. HR being a very dynamic and crucial aspect in mature industries faces equally important and dynamic HR challenges. For instance, some of the challenges that are often faced by mature industries are talent management, retention, change management, compensation and perks, competition with newer emerging sectors, employee turnover to competition, corporate branding for attracting $\mathrm{HR}$, return on investments done on training, regulations and adherence to best practices [7], [8].

In an emerging sector, since there are no precedents available, they mostly rely on experimentation style of management, where people learn from making costly mistakes. Some of the challenges that emerging sector faces are team building (right person for the right job), attracting the right $\mathrm{HR}$, skill development, retention, offering something better than mature sectors, ROI (investment done on hiring and training), process development, employee management and conflict resolution [6].

\section{ANALYSIS OF FINDINGS}

A survey was conducted and the HR departments of 10 banks were approached out of which 6 responded. In IT sector, the survey questionnaire was sent to the HR department of 50 companies and 19 responded within time. There was no proper HR department in most of the IT firms.

Generic details were fetched from the companies, such as their years of operation, (Figure 2).

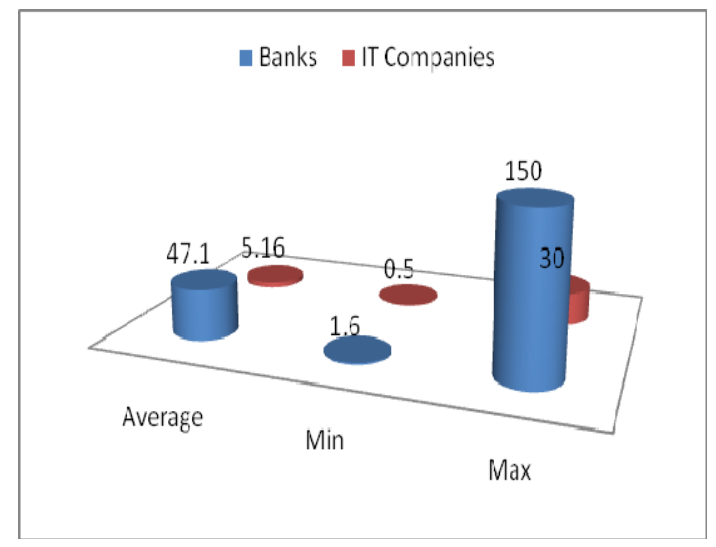

Figure 2: Years in Operations

The average year in operation was 47 years for banks. In IT companies, the average year in operation was 5 years. The year in operation depicts the maturity of the company.
In case of Dubai Islamic Bank Pakistan, this is a new venture in Pakistan, however globally they are in operations since 1975. The average year in operation is important to know in understanding what level of challenges banks and IT companies face.

The number of offices of each organization was also known through the survey questions (Figure 3).

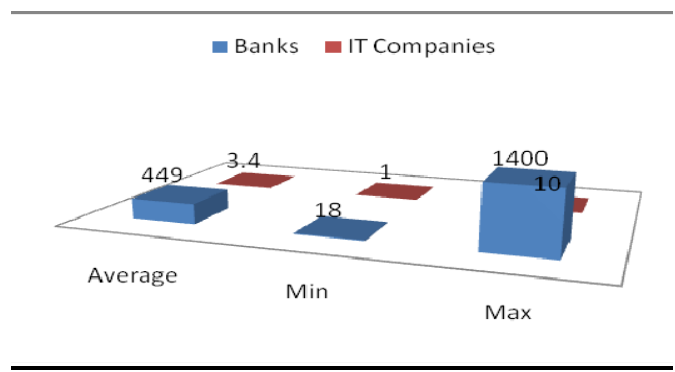

Figure 3: Number of Office

The number of offices of each firm again tells us about the size and issues that are likely to be faced by companies. The HR issues are very much dependent upon the number of professionals in an organization and how geographically dispersed they are. Managing HR in one location and managing HR that is widely spread leads to different kinds of HR issues.

The survey also enquired about the number of workforce within each organization (Figure 4).

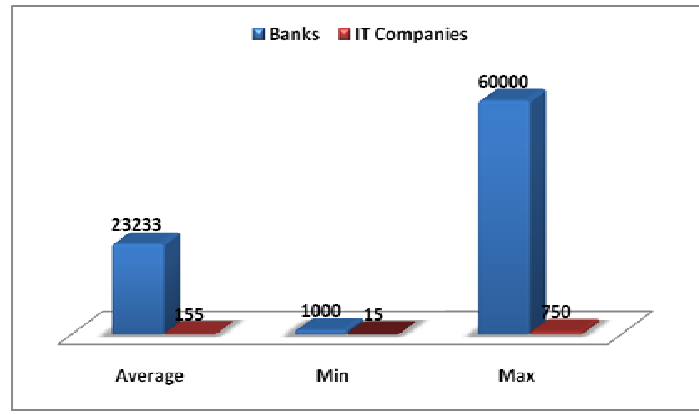

Figure 4: Number of Work Force

The number of work force show the nature and criticality of HR issues, since the strength of an organization in terms of workforce is very important. It also gives us a quick comparison in banks and IT companies regarding the averages, minimum and maximum number of employees. The size of the organization is also very important, as in large organizations issues of "lost on the jungle feeling" arises that leads to issues of motivation and conflict resolution as we have seen in banks.

All the banks that responded possess a formal HR department; however, in IT companies out of 19 only 15 possess a formal HR department. Organizations were inquired about the number of people they possess in their

Journal of Independent Studies and Research (JISR) - Management and Social Sciences \& Economics Volume 6, Number 2, July 2008 
HR department, the results of which are mentioned in Figure 5.

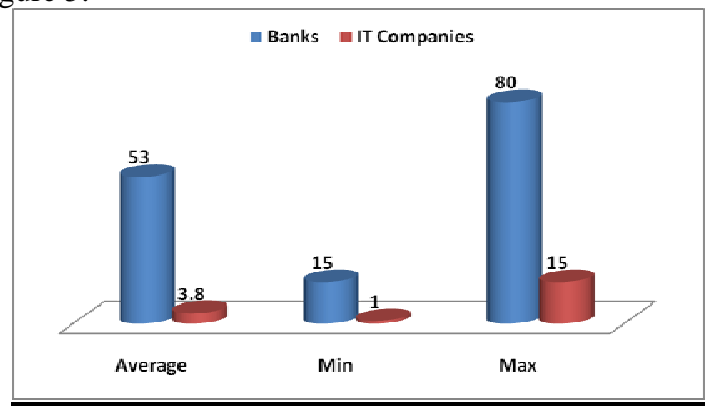

Figure 5: HR Department Strength

In banks, minimum HR strength is 15 and maximum is 80 in the HR department. However, in IT companies, minimum HR strength is 1 . Most of the responses were 2 and 3 and therefore the average HR strength came out to be 3.8 .

Upon inquiring, it was known that in IT companies, HR professionals' primary job was HR related; however, they were also involved in a lot of administrative work. It is this reason that in most of the IT firms, there is a department named 'HR \& Admin' rather than only HR department. However, in a bank, HR department was a separate department and they were not involved in administration.

To understand the affectivity of HR professionals, we calculated employee to HR ratio as mentioned in Table 1.

Table 1: Employee: HR Ratio

\begin{tabular}{|l|l|l|}
\hline & Banks & IT Companies \\
\hline Employee/HR Ratio & $438: 1$ & $41: 1$ \\
\hline
\end{tabular}

On an average, one HR professional is looking after or managing 438 professionals in a bank; and in IT sector, 41 professionals are being managed by 1 HR person. Here we must not forget that in banks there are mature processes and the HR departments who contribute to the organizations on strategic level. On the other hand, the result is compliant to the fact that in bigger organizations, employees tend to get a "Lost in the Jungle' feeling. When a HR executive has this much load, they tend to overlook a lot of important issues and as a result the employees complain about the inefficiency of HR and are unsatisfied.

The ratio shows a better figure in the IT sector that is $1 \mathrm{HR}$ professional is taking care of 41 resources. However, this should be kept in mind that on an average, IT firms do not have dedicated HR people in their organization nor do they play any strategic role of HR management in their companies as can be seen in the next table. The positive aspect here is that in small organizations, the performance management is done more effectively as there are no comprehensive hierarchies.
The survey also inquires about the top HR functions that the HR department performs in their respective departments (Figure 6).

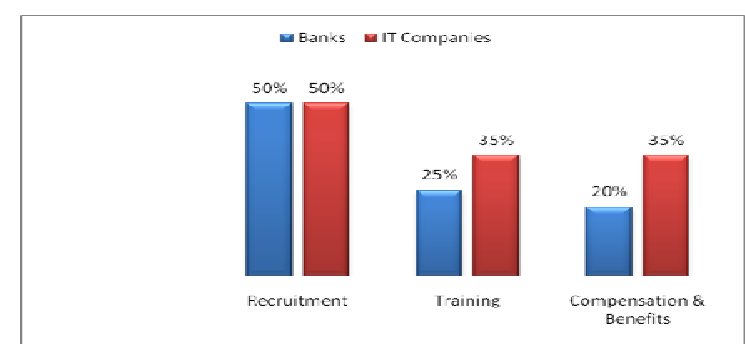

Figure 6: Top 3 HR Functions

In banks and IT firms, 50\% of the HR time is spent on recruitment. Different responses were received like staffing, hiring, selection, and interview. Thus, we grouped them under one heading of Recruitment. Bank HR is spending $25 \%$ of the time in training and development; whereas, in IT Company, 35\% of the time is spent on training and skill development. The $3^{\text {rd }}$ major task is working on compensation and benefit in which banks are spending 20\% and IT companies are spending 35\% of their time. Once again this should be kept in mind that on an average, IT firms do not have dedicated HR people in their organizations nor do they have enough resources; thus, unlike banks, where there is a huge staff taking care of recruitment, training and compensation, IT companies have 1 or 2 people to take care of all HR functions.

The top 3 issues like lack of skilled human resources, retention of employees and compensation designing, reported by banks and IT firms were the same. Banks, being a mature industry, face the same issues as faced by the emerging sector of IT. The fourth and fifth issues depict issues that are faced by mature and upcoming sectors. Banks are facing issues of managing motivation and succession planning. However, IT firms are going through the issues of skill development, as they are moving in a high-paced technically advanced domain and brain drain due to the international market pull. Motivation issues and succession planning are the issues likely to be faced in large organizations as the "Lost in Jungle' feeling among the employees de-motivate them and upon getting no direction they tend to lose the rigor and charm in their work.

The banks and IT firms were asked about the reasons for the issues they face and both the sectors mentioned that quality workforce is not available in the market. The banks also mentioned that since they are facing a lot of change, they are facing issues due to Change Management. Banking sector is growing and thus the existing employees and potential candidates get good offers, which are raising the issue of designing the competitive compensation and benefits structure.

Journal of Independent Studies and Research (JISR) - Management and Social Sciences \& Economics Volume 6, Number 2, July 2008 
IT companies, on the other hand, highlighted a very critical aspect. They mentioned that they face HR issues because there is a huge gap between what is offered by the academia and what is expected by the industry and thus there is a huge gap between the demand and supply of skilled people. The skilled professionals who are available are in high demand and are offered huge packages by other companies within the industry. Another important reason is that since IT companies are operating in a very sensitive and dynamic domain, the work pressure and the odd timings of operation is a major reason due to which they face HR challenges.

Very few respondents specified the reasons of HR issues specific to their industry. Banks mentioned that they possess rigid HR policies that are to be followed and which hinder with the operational flexibility. Since new banks are coming up and offer better packages, they need to readjust their existing packages very frequently. They also mentioned that in banks, they need to adhere to all the regulations by SBP, which cause an extra stress on the resources, and they tend to switch jobs.

IT companies blame the odd working hours and lack of work ethics as the reason for HR challenges that they face. In IT, it is a frequent practice that what is committed by the candidate at the time of hiring is brutally dishonored. For instance, if a professional is expected to give a 1 month notice at the time of resignation, it will not be honored. Similarly, if a bonus or an increment is promised by the employer, it is not being dispersed accordingly and thus the credibility of employee and employer's relationship gets shattered. Another issue with IT companies is that since all are knowledge workers, and due to information technology, the HR of this sector is way too knowledgeable and thus HR professionals have a lot of job options available both nationally and internationally.

Upon asking what measures are being taken to cater to the HR challenges, the majority responded that competitive packages should be given backed by proper salary surveys. Both sectors also suggested investing on the training and grooming of their HR to retain them.

Banks are also working on 'Work and Life Balance' initiatives and smoothening up the communication lines within organizations to reduce the frustration level, which is one of the major causes of employee turnover and is very effective for raising employee morale. Apart from that bank are also working on the succession plan and giving employees' a vision for maximum retention.

IT companies are working on performance management and consulting academia with their requirements so that graduates are ready for the industry when they enter the market.
Out of 6, 3 bank HR professionals said they feel the challenges they are facing today will remain the same after 3 years and rest mentioned otherwise. Majority of the IT HR people expected the HR challenges that they are facing today would change.

The responses enabled us to understand the caliber of HR professionals. HR is a department that plays a very crucial role in the growth and sustainability of a company and one of the major roles of HR is to foresee change and act accordingly. The responses show that HR is expecting similar situations prevailing by the next 3 years.

Few banks who predicted that down lane by next three years, the HR challenges will change, mentioned that banking sector is currently facing boom, will be stagnant in near future and a series of layoffs will be observed. This will lead to retention of high performers, which will be a crucial task for HR people. Since they expect change, adaptability to change will be another major and ongoing challenge for HR people. Banks also gave a new dimension that since they are very much confidentiality conscious, they fear the issue of information security will rise with the rapid development on the technology side.

On the IT front, HR foresees that acquiring the right HR will be a major task. They see that the pull from the international market will increase because on going brain drain will lead to fewer resources in the market and thus severe issue will be raised to find the right person for the right job.

Social, economical and political events also have a significant impact on the industry issues.

The HR professionals of banks feel that boom in the banking sector is expected in the next three years. State Bank regulations are changing rapidly, keeping in view the dynamism of banking sector.

Political instability can cause significant impact on banking industry, as the major catalysts for growth in this sector are consistency in the economic policy and foreign investment. Mergers and acquisitions among banks are another aspect that contributes towards ever increasing HR challenges.

The HR professionals of IT companies feel that the entrance of Chinese industries within the next 3 years will have a significant impact on the IT exports of Pakistan. Most Chinese schools have made English the compulsory language, thus the business of the call center industry will be taken over by the Chinese due to their low cost labor and understanding of the business industry. Private sectors' investment in IT industry is a very healthy sign for the growth of IT sector and demands for quality HR is likely to go up. 
Government has recognized the potential of call center services and is also taking positive steps for providing positive incentives for the growth of this sector. On the other side, there is a lot of uncertainty in Pakistan owing to multiple mishaps that have happened in the past. Previously, the 9/11 incident adversely affected the business and there was excess capital and manpower in the market due to no business and the massive layoffs. In future, a similar incident can lead to such conditions again.

Abrupt Law and Order situation in the country can have adverse affects on the foreign investments in this industry. Utilities (electricity failure), increased cost of setup and operation have caused SMEs and startups to face huge problems as the cost is going up and expected returns on investment get shaky.

Political situations, inflation, IT sector growth, below average resources in market etc would remain the major issues and will raise major challenges for HR in future.

\section{CONCLUSION}

The research under study was conducted to understand and provide a comparison of what kinds of HR challenges are being faced by a mature sector and by an emerging sector. One of the key aspects of this study was to identify what lessons can be learnt from a mature sector that can be avoided by an emerging one for the betterment of the industry and to assist HR professionals of the emerging sectors accordingly in predicting and foreseeing the challenges lying ahead.

The interesting fact that was observed is that the top three issues namely lack of skilled human resources, retention of employees and compensation designing faced by Banking and IT sectors were nearly the same. Pretty much the rectification measures expected to be taken by them were also same.

Based on the findings and analysis, we can say that being a mature sector, we see considerable investment by banks in the HR. All Banks possess a formal and dedicated HR department and they have sophisticated processes, procedures and policies that have been evolved over a period of time. Compared to that, very few companies in IT have shown importance of HR as they have sufficient number of people in the HR department. Majority of the IT firms do not have a formal and dedicated HR Department and the HR professionals are doing administrative work as well. That is why, in IT firms, majority have 'HR and Admin' department and HR people are not playing any strategic role in the organization.

Since both sectors have shown concerns about HR, banks seem to work on them seriously by making considerable efforts and investments. On the contrary, IT companies complain about HR issues but are not willing to invest any time and resources on this area since IT industries still do not realize the importance of a proper HR department nor any strategic input is expected from the HR people. For an IT company, HR merely means a department that generates $\mathrm{CVs}$ and maintains documents and logs of attendance. The true rationale behind having an HR department is yet to be explored by the IT companies.

It is also worth mentioning that majority of IT companies do not have a formal HR department. They have merely 1 or 2 people as HR executives who maintain the documents, log of employees, and are mostly involved in administrative tasks rather than actual HR work. The result is the fact that HR is not part of the overall Strategic Planning in IT companies.

The employee to HR professional ratio shows that even in large organizations, one HR professional is managing a large number of workforces and the result is quite as expected that there is a huge negativity against the HR department by the employees. They feel that the HR is not working effectively. In IT sector, we have observed that the ratio is low but HR is not playing a significant role in this sector and is only maintaining logs and documents most of the time. HR is not a strategic issue yet in IT and its true importance is yet to be recognized by the IT companies.

Few key IT players are moving in that direction, however, still it is not sufficient. The banking sector is investing heavily in the future planning but this drive is still missing in the IT sector.

\section{AREA FOR FURTHER RESEARCH}

The area for further research is an in-depth analysis of the HR issues and their reasons on a wider scale involving 5-8 leading industries to understand the HR challenges further in detail.

\section{REFERENCES}

[1] PricewaterhouseCoopers, 2005 on behalf of World Federation of Personnel Management Associations (WFPMA) Global HR Challenges.

[2] SBP BSC (Bank), 2005, Human Resource Management in Banking Sector-An Overview of Performance, SBP.

[3] Bhat, Sudhindra, 'Managing Challenges in Banking Industry'

http://www.indianmba.com/Faculty_Column/FC173/f c173.html Date accessed: June 25, 2007.

[4] IT Industry Overview conducted by PSEB in 2006, Industry HR Projections given by PSEB in 2005, http://www.pseb.org.pk/page.php?pid=39 Date accessed: June 26, 2007. 
[5] HR Challenges for the IT Industry by Executive Search Consultants, http://mcs-india.net/article-hrchallenges-for-it-industry.htm

Date accessed: June 23, 2007.

[6] Industry Lifecycle by 'eNotes.com,

http://www.enotes.com/small-business-

encyclopedia/industry-life-cycle

Date accessed: June 26, 2007

[7] Cattell, Alan, 2005, Value-Redefining the priorities in CPD for HRD Professionals, 6th International Conference at HRD Practices and Research Across Europe, Leeds, May.

[8] Raman, S. Raghu \& G. Balasubramanian, Assistant Professor and Professor, 2007, Managing People in a New Industry: A Case Study of High-End BPO Organization, from Institute of Financial Management and Research, Chennai, India.

Journal of Independent Studies and Research (JISR) - Management and Social Sciences \& Economics Volume 6, Number 2, July 2008 